\title{
MIGRACIJE V ČASU PANDEMIJE COVID-19: MEJE MOBILNOSTI IN DRUŽBENE NEENAKOSTI ${ }^{* * 1}$
}

\begin{abstract}
Povzetek. Članek obravnava povezavo med pandemijo covid-19, migracijami in izključenostjo iz varnega prostora bivanja. Temeljni premislek naslavlja kompleksnost novih okoliščin migracijskih in begunskih poti, ko so meje postale neprehodne za vse, ne le za begunce, hkrati pa se vprašanju mobilnosti preko meja pridruži še strašljiva dvojica kužnega drugega. S koronsko krizo je sedentarnost postala nov imperativ globalne mobilnosti. Najina teza je, da so meje pandemije postale meje mobilnosti, pri čemer imperativ \#ostanidoma kot glavna točka protikoronskih politik spregleda družbene skupine in številne posameznike z družbenega roba, ki nimajo dostopa do varnega prostora izolacije, med njimi tudi migrante in begunce.

Ključni pojmi: pandemija covid-19, migracije, begunci, javno zdravje, kužni drugi
\end{abstract}

\section{Uvod: pandemija in migracije}

Globalna pandemija virusa covid-19 in vpliv, ki ga ima na naša vsakodnevna življenja, jasno kažeta, da gre za tematiko, ki ne bo imela samo daljnosežnih javnozdravstvenih in epidemioloških posledic, temveč tudi družbene, kulturne in ekonomske. A vendarle so bile zlasti v začetku njenega trajanja v Sloveniji in Evropi - okvirno od februarja 2020 naprej - v ospredju njene zdravstvene implikacije, ki se nanašajo na preprečevanje in obvladovanje števila okužb in zmanjševanje števila smrtnih izidov. Priporočila globalnih akterjev na področju javnega zdravja, predvsem Svetovne zdravstvene organizacije (WHO), so bila, četudi so jih vlade v praksi interpretirale in udejanjale na različne načine, namreč usmerjena zlasti k zagotavljanju primernih higienskih razmer za zajezitev okužb, na primer z umivanjem rok

* Dr. Simona Zavratnik, docentka, Fakulteta za družbene vede, Ljubljana, Slovenija; Dr. Sanja Cukut Krilić, znanstvena sodelavka, ZRC SAZU, Ljubljana, Slovenija.

** Izvirni znanstveni članek. DOI: 10.51936/tip.58.1.72-87

1 C̆lanek je nastal v okviru projekta Politični in medijski populizem: "begunska kriza"v Sloveniji in Avstriji (J5-9445), raziskovalnega programa Sociološki vidiki trajnostnega družbenoprostorskega in kadrovskega razvoja Slovenije v Evropi (P5-0181), ki ju financira ARRS, Javna agencija za raziskovalno dejavnost in v okviru projekta Opismenjevanje o motnjah razpoloženja in osebnostnih motnjah (številka pogodbe C2711-20-708328). 
in razkuževanjem, s pitjem primerne količine tekočine in $z$ vzdrževanjem prostorske oziroma fizične razdalje. ${ }^{2}$

V tem besedilu obravnavava povezavo med pandemijo covid-19 in migracijami, zlasti z vidika marginalizacije migrantov in beguncev kot ranljivih družbenih skupin in posledično procesov poglabljanja družbenih neenakosti. Temeljni premislek naslavlja kompleksnost novih okoliščin migracijskih in begunskih poti, ko so meje postale neprehodne za vse, ne le za begunke in begunce, in je sedentarnost postala nov imperativ globalne mobilnosti. Raziskovalno vprašanje se nanaša na tri temeljne relacije, na podlagi katerih analiziramo spremembe na področju migracijskih in azilnih politik ter nekatere nove oblike zaznav migrantov $\mathrm{v}$ povezavi $\mathrm{z}$ virusom in globalno mobilnostjo.

V članku se osredotočava na naslednja raziskovalna vprašanja v odnosu med pandemijo virusa covid-19 in migracijami: 1 . Kako javne politike na področju migracij in azila odgovarjajo na spremenjene okoliščine mednarodne mobilnosti, to je na zastoj mobilnosti? Pri tem izhajava iz predpostavke, da je zastoj mobilnosti povečal negotovosti in ranljivosti, ki jih izkušajo ljudje na poti, ter zaostril temeljno človekovo pravico dostopa do azila. 2. Kako se vprašanje nemobilnosti povezuje s konceptom kužnega drugega, kot se le-ta artikulira na presečnosti konceptov migracij, varnosti in javnega zdravja? Izhajava iz pozicije obstoječe sekuritizacije tako migracij kot tudi zdravja oziroma bolezni, v okviru katere javne politike begunca/ migranta pogosto prikazujejo kot kužnega drugega. 3. In nazadnje, kako se v obdobju pandemije virusa covid-19 poglabljajo obstoječi oziroma nastajajo novi rasizmi in nacionalizmi? Pri tem izhajava iz spoznanj najnovejših študij, ki globalne migracije postavljajo v kontekst prenosa virusa in posledično novih rasističnih delitev, npr. do prebivalcev Kitajske.

Osrednja teza v članku je, da so meje pandemije postale meje mobilnosti, pri čemer imperativ \#ostanidoma kot glavna točka protikoronskih politik spregleda družbene skupine in številne posameznike $z$ družbenega roba, ki nimajo dostopa do varnega prostora (samo)izolacije. V času vseprisotnosti poziva \#ostanidoma je trendovskemu geslu nujno treba dodati, da nimajo niti vsi posamezniki niti vse družbene skupine privilegija ostati v varnem okolju in izolirani pred pandemijo. Tem vprašanjem je $\mathrm{v}$ začetku aprila 2020 skupina raziskovalk in študentk namenila blog \#Ostanidoma: migracije, begunci in covid-19 (https://virusnimameja.com), ${ }^{3}$ platformo družboslovnih misli z družbenega obrobja, ki predvsem opozarja na ranljivosti ljudi, ki si ne morejo privoščiti \#ostanidoma, ker te možnosti preprosto nimajo.

2 Podrobneje o ukrepih glej: https://www.who.int/emergencies/diseases/novel-coronavirus-2019.

3 Kolektiv avtoric blogerk smo Simona Zavratnik (FDV), Špela Perner, Anja Zafošnik, Špela Vovk, Klara Andlovic (vse študentke magistrskega študija sociologije na FDV) in Sanja Cukut Krilić (ZRC SAZU). 


\section{Metodologija: virtualno zbrani podatki}

V razmerah zaprtih nacionalnih in celo občinskih meja se je naše raziskovanje preselilo v virtualni svet, kjer so se vzpostavljale sodobne digitalne skupnosti beguncev, migrantov, aktivistov, raziskovalcev, lokalnih prebivalcev in drugih akterjev na področju podpore ljudem na poteh ali v izolacijah vzdolž prekinjenih migracijskih in begunskih poti. Digitalne tehnologije, tako osrednjega pomena za mobilnost, da sodobne begunce opisujemo kot digitalne begunce (Zavratnik in Cukut Krilić, 2020), so v času pandemije postale zares ključne in nepogrešljive tudi pri raziskovalnem delu. Aplikacije in spletna orodja so tako postala naše osrednje metodološko pomagalo za izvedbo intervjujev in spremljanje sprememb na terenu; služile so nam za zbiranje podatkov, za pogovore z eksperti in aktivisti na terenu - vzdolž tako imenovane balkanske migracijske poti, od Grčije, prek Srbije, Bosne in Hercegovine, Hrvaške in Slovenije do Italije, a tudi v širšem globalnem prostoru - kot tudi za sodelovanje na spletnih delavnicah (webinarjih). Podatke $\mathrm{v}$ tem članku smo zbirale $\mathrm{z}$ naslednjimi metodami:

1. Intervjuji z eksperti. Prek spleta je bilo izvedenih šest pogovorov $s$ poznavalci stanja na terenu, in sicer $\mathrm{z}$ medicinsko delavko $\mathrm{v}$ begunskem centru v Grčiji, z novinarko v Grčiji ter štirimi aktivisti oziroma strokovnimi delavci, ki so v stiku z begunci na terenu ali neposredno zagotavljajo pomoč, in sicer v Italiji, Sloveniji, na Hrvaškem in na več lokacijah vzdolž t. i. balkanske poti. ${ }^{4}$ Nekateri pogovori, ki jih uporabljamo za naše primarne vire, so delno ali v celoti objavljeni na blogu (z medicinsko delavko in aktivistom) (Perner, 2020; Zafošnik, 2020a), pri drugih uporabljamo zbrane podatke iz virtualnih pogovorov. Slednje je na blogu dokumentirano v obliki več avtorskih tekstov (npr. o pomenu NVO v Sloveniji in širšem prostoru, delovanju NVO v Italiji, o medijskem poročanju o beguncih v obdobju epidemije virusa covid-19 v Sloveniji in Grčiji itd.) (Lešnik, 2020; Lihtenvalner, 2020; Vezjak, 2020; Zafošnik, 2020b).

4 Intervjuji so bili izvedeni prek aplikacij Zoom, Viber, Messenger ali telefonsko. Intervjuja z aktivistko iz ZDA in aktivistom iz Španije sta objavljena v skrajšani obliki na blogu. Glej: https://virusnimameja.com/2020/04/07/iz-terena-pogovor-s-prostovoljko-v-grskih-begunskih-centrih/ (7. 4. 2020) in https:// virusnimameja.com/2020/05/10/s-terena-delo-z-begunci-na-balkanu-v-casu-razmaha-covid-19/ (10. 5. 2020).

Intervjuja s predstavnikom Slovenske filantropije (7. 4. 2020) in Karitasa (8. 4. 2020) o spopadanju nevladnih organizacij s covidom-19 sta bila izvedena telefonsko (dokumentacija: aktiv blogerk). Glej tudi besedilo: https://virusnimameja.com/2020/04/08/nevladne-organizacije-in-covid-19-zakaj-so-lahko-pomembne-za-migrante-begunce-nas/ (8. 4. 2020).

Več pogovorov z aktivistko in novinarko v Atenah je potekalo v obdobju od 30. 4. do 30. 5. prek aplikacij Viber in Messenger. Glej tudi tekst: https://virusnimameja.com/2020/05/23/grska-epidemija-ksenofobije-in-rasizma/ (23. 5. 2020); nadalje smo se z aktivistko o situaciji v Italiji pogovarjali v živo, prek telefona in prek aplikacije Messenger (v obdobju od 20. aprila do 2. junija). Glej tudi besedilo: https:// virusnimameja.com/2020/06/04/italija-in-begunci-v-mesta-ali-v-begunska-taborisca/ (4. 6. 2020). 
2. Pogovori na spletnih seminarjih. Avtorice bloga smo sodelovale na treh specializiranih spletnih delavnicah, ki so obravnavale položaj migrantov in/ali beguncev v pandemiji virusa covid-19 v različnih državah, predvsem na balkanski poti, v EU ali globalno. ${ }^{5}$ Glavni izsledki in poudarki so objavljeni na blogu v kratkih tekstih, poročilih in strokovnih mnenjih, ki obravnavajo vplive pandemije na begunce $\mathrm{v}$ globalnem, regionalnem ali lokalnem oziru. V naši analizi je poudarjena evropska razsežnost, vključujoč balkansko pot (Cukut Krilić, 2020a; Cukut Krilić in Zafošnik, 2020; Perner in Zafošnik, 2020).

3. Sekundarni podatki vključujejo znanstveno literaturo s področja pandemije virusa covid-19 v povezavi z migracijami (npr. recenzija dela Meje epidemije iz 2020, ki obravnava covid-19 in delavce migrante in migrantke v Indiji) ${ }^{6}$ (Cukut Krilić, 2020b), poročila in ekspertize globalnih akterjev na področju begunstva in migracij, ${ }^{7}$ zlasti UNHCR (The UN Refugee Agency) (npr. specializiran blog UNHCR, 2020), ${ }^{8}$ ter relevantno širšo znanstveno literaturo s področja mobilnosti, migracij in javnega zdravja.

Zbrano gradivo v obliki primarnih virov o položaju na terenu smo pridobile v obdobju dveh mesecev in pol, od sredine marca do konca maja 2020. Podatke smo v celotnem obsegu ali v skrajšanih verzijah v obliki poročil, strokovnih mnenj in komentarjev sproti objavljale na blogu. Empirično gradivo je bilo objavljeno v obdobju dveh mesecev, in sicer od 7. aprila 2020 do vključno 6. junija 2020; v tem času je nastalo in bilo objavljenih 23 prispevkov.

\section{Teoretski okvir: migracije in javno zdravje}

Študije kažejo, da so migranti skupina prebivalstva, ki ima zaradi mnogoterih socialno-ekonomskih dejavnikov in različnih oblik diskriminacije pogosto slabši dostop do zdravstvene oskrbe ter je še dodatno ranljiva za neugodne zdravstvene izide (Bofulin in Bešter, 2010; Guadagno, 2020; Lipovec Čebron, 2010; Vignier in Bouchaud, 2018). Kljub temu dejstvu v govoru vladnih predstavnikov pogosto zaznamo, da so migranti nosilci in prenašalci določenih nalezljivih bolezni, pred katerimi je domnevno treba zaščititi domače prebivalstvo. Del takega govora v javnosti je tudi teza o slabših higienskih standardih nekaterih skupin migrantov, kar naj bi bila

5 Podrobneje glej $v$ poročilih s spletnih seminarjev: https://virusnimameja.com/2020/04/07/ webinar-kaj-pandemija-covid-19-pomeni-za-begunce-po-svetu/ (7. 4. 2020), https://virusnimameja. com/2020/04/25/webinar-o-beguncih-na-balkanski-poti-v-casu-covid-19/(25. 4. 2020), https://virusnimameja.com/2020/05/12/webinar-vpliv-covid-19-na-balkanski-poti/(12. 5. 2020).

6 Glej: https://virusnimameja.com/2020/05/21/recenzija-zbornika-meje-epidemije-covid-19-in-migrantski-delavci-in-delavke/.

7 Glej:https://virusnimameja.com/2020/04/07/begunci-v-covid-19-krizi-odziv-globalnih-akterjev/.

8 Glej: https://www.unhcr.org/news/stories/2020/4/5e79e2410/live-blog-refugees-covid-19-crisis. html. 
posledica njihovih domnevnih »kulturnih posebnosti«. Pri tem je povsem spregledano dejansko stanje, namreč dejstvo, da ljudje na poti in v kolektivnih begunskih centrih pogosto nimajo osnovnih možnosti niti za vzdrževanje higienskega minimuma.

Predstave o zdravju in kužnosti v povezavi z mobilnostjo prebivalstva so med seboj neločljivo povezane (Greenaway in Gushulak, 2017), zato ni presenetljivo, da so se skozi zgodovino uveljavile in do danes ohranile prakse preverjanja in zdravstvenega testiranja ljudi, ki so prihajali od zunaj. Zapise o povezavi med izbruhi nalezljivih bolezni in mobilnostjo prebivalstva najdemo že v antični Grčiji in Rimu, medtem ko se je karantena kot praksa za zajezitev okužb, ki so takrat od zunaj prihajale zlasti z ladij, uveljavila v 14. stoletju z izbruhom bubonske kuge. V tistem času je bila sicer odreditev karantene bolj vezana na potovanja zaradi trgovinske dejavnosti kot pa na migracije same (Greenaway in Gushulak, 2017). Četudi so bile bolezni pogosto prepoznane kot del mednarodnih potovanj in procesov kolonizacije in grajenja imperijev, pa so bile migracije $v$ kasnejših obdobjih (na primer Ircev v ZDA v prvi polovici devetnajstega stoletja, ki naj bi v ZDA prinašali kolero) pomemben dejavnik utrjevanja praks karantene kot enega od načinov varovanja javnega zdravja prebivalstva (ibid.). V drugi polovici 76 dvajsetega stoletja je prebivalstvo postajalo vedno bolj mobilno in povezano, k čemur sta pripomogla razmah letalskega prometa in mednarodna potovanja, slednja pa so bolj kot migracije same postala ključni označevalec in domnevni razlog za globalno širjenje epidemij različnih nalezljivih bolezni, na primer virusov SARS, zika itn. (ibid.). Nekatere države, na primer Nemčija, Francija in Združeno kraljestvo, še danes v duhu dediščine devetnajstega stoletja uporabljajo za oceno zdravstvenih tveganj pri mednarodnih migracijah ukrepe, kot je npr. presejanje migrantov za tuberkulozo, na podlagi katerega lahko zavrnejo vstop ali odredijo karanteno (Taylor $\mathrm{v}$ Dingwall et al., 2013); to v širšem kontekstu štejemo za del vladovanja in nadzora nad migracijami (Scott et al., 2014; Zavratnik in Cukut Krilić, 2018).

Sociološko gledano so namreč bolezni in z njimi povezane epidemije vir negotovosti in nestabilnosti, celo družbenih kriz, pri čemer sociologijo kot družboslovno znanost zanima, kako družbe identificirajo bolezni, kako se nanje odzivajo in kakšne so njihove širše družbene implikacije (Dingwall et al., 2013). S tega vidika je raziskovanje položaja ljudi na obrobjih družbe (na primer migrantov in oseb z izkušnjo brezdomstva) nujno za boljše razumevanje na videz samoumevnih in neproblematičnih praks vsakodnevnega življenja, kot so skrb za osebno higieno, dostop do pitne vode ipd., skozi katere so se v pandemiji jasno izrisovale nove družbene neenakosti in ranljivosti. Na ta način jasno pokažemo, da sta vprašanji javnega zdravja in varnosti naroda (kot osrednja elementa državnih zdravstvenih politik) neločljivo povezani. 
Nadzor nad gibanjem prebivalstva je bil že pred epidemijo ključna značilnost migracijskih politik večine držav, pri čemer so se države opirale na sofisticirane informacijske podatkovne baze, katerih arhivi so omogočali prebiranje med zaželenimi in nezaželenimi migranti, kar v temelju določa tudi različno raven pravic, ki jih določene skupine migrantov imajo (Scott et al., 2014; Zavratnik in Cukut Krilić, 2018). Kot poudarja Emily McDonnell (2020), so milijoni ljudi že pred epidemijo izkušali učinke globalnega režima nemobilnosti. Pri tem tudi "percepcije javnosti sledijo javnim politikam, ki migracije klasificirajo skozi ustaljene kategorije zaželenih vs. nezaželenih ter posledično legitimnih vs. nelegitimnih migrantov, $s$ tem pa se $\mathrm{v}$ javnih politikah definirane dihotomije utrjujejo v percepcijah javnosti« (Zavratnik et al., 2017). Na ta način so migracijski klasifikacijski mehanizmi postali operativni na mejah nacionalnih držav, država pa ima moč oblikovanja hierarhij posameznih skupin migrantov (Scott et al., 2014).

Možnost dostopa do globalne mobilnostne infrastrukture je močno povezana s strategijami eksternalizacije vlad držav Evropske unije, ZDA in Avstralije, ki skušajo z različnimi praksami, kot so sistemi viz, sankcije za prevoznike, pridržanja in prestrezanja na morju in kopnem, preprečiti gibanje prosilcev za azil, beguncev in drugih migrantov na njihova ozemlja (McDonnell, 2020). Pri tem imajo v sodobnosti ključno vlogo sodobne tehnologije bionadzora, kot so droni in aplikacije za sledenje. Ta pomagala so bila že prej sestavni del upravljanja z migracijami, s pandemijo pa se je njihova vloga orodja ne le za sledenje gibanja ljudi, temveč tudi gibanja virusa, le še okrepila (McDonnell, 2020; Molnar, 2020), kar kaže na nadaljnjo sekuritizacijo ne samo migracij, temveč tudi zdravja in bolezni.

Vloga klasifikacije v praksah discipliniranja, ki zadevajo migranta kot drugega, se na izrazit način kaže tudi v nadzoru migrantov kot možnega izvora okužb in bolezni, s čimer se temi migracij in javnega zdravja znova neločljivo povežeta. Napetosti in strahovi, vezani na prepustne meje, kot tudi prakse, ki naj bi zmanjševale tveganje njihovega prehoda, se namreč neposredno artikulirajo $\mathrm{v}$ strahovih pred mobilnimi telesi migrantov (Scott et al., 2014). Ti v situaciji pandemije niso ranljivi le zaradi statusa migranta, temveč njihovo ranljivost lociramo na presečišču razreda, rase, spola in družbenega statusa: srečujejo se s specifičnimi ovirami, zaradi katerih imajo slabši dostop do zdravstvene oskrbe, so spregledani v programih zagotavljanja blaginje, bojijo se stigmatizacije, nekateri tudi aretacij in deportacij (Guadagno, 2020). Pandemija je torej pokazala na dejstvo, da obstoječe zdravstvene in druge neenakosti pomembno povečujejo ranljivosti za bolezen in krepijo neenake družbene strukture (Pertek et al., 2020). 


\section{Empirični rezultati: zastoj mobilnosti, kužnost, rasizem}

Izhajajoč iz teoretičnih obravnav odnosa med pandemijo virusa covid-19 in migracijami, predvsem $z$ vidika javnega zdravja in hkratne marginalizacije ranljivih družbenih skupin, v empiričnem delu podajava temeljne ugotovitve naše raziskave, pri čemer sledimo trem uvodoma zastavljenim vprašanjem.

\section{Politike in institucionalni odgovori}

Najprej iščeva odgovor na vprašanje, kako javne politike na področju migracij in azila odgovarjajo na novo globalno realnost zastoja mobilnosti in kako se v tej situaciji spreminjajo režimi upravljanja migracij in azilni postopki. Naša empirična raziskava je pokazala dva temeljna problema: prvi je globalni zastoj mobilnosti, kar je za begunce in migrante na poteh pomenilo, da so (p)ostali ujeti v različnih nepredvidljivih situacijah, drugi pa je izjemno omejen dostop do azila. Podatki s terena kažejo, da se številni begunski centri po svetu spopadajo z ovirami, ki so prisotne še iz časov pred razmahom virusa, le da so te zdaj potencirane. Eksperti poudarjajo, da prenaseljenost taborišč vpliva na duševno zdravje prebivajočih, realnost ljudi, ujetih v šotore, pa na globalni ravni kliče k dvema strategijama: preselitvi ljudi z natrpanih lokacij v centre širom Evrope, ki imajo proste kapacitete (s čimer bi lahko omogočili boljše higienske in na splošno verjetno tudi življenjske razmere) in k urejanju njihovega pravnega statusa (Perner in Zafošnik, 2020).

Dodaten problem je nasilje, ki je bilo v našem raziskovanju evidentirano na primer v centrih v Bosni in Hercegovini (Bihač) in Srbiji (Krnjača), begunci so dehumanizirani in objekt najrazličnejših nasilnih praks, medtem ko na primer upravitelj centrov v Bosni, Mednarodna organizacija za migracije (IOM), ne podaja odgovorov in se ne odziva ustrezno na tovrstne kršitve človekovih pravic (Cukut Krilić in Zafošnik, 2020). Predstavniki NVO in prostovoljci, ki delujejo na terenu, namreč poročajo, da so povzročitelji nasilja pogosto prav pripadniki javnih služb in institucij, zlasti zasebne varnostne službe $\mathrm{v}$ centrih ter policija na mejah in ulicah (ibid.). Zelo problematična je praksa nezakonitega vračanja beguncev na mejah (t.i. pushback), ki se še vedno izvaja vzdolž celotne balkanske poti vključno z Italijo, na Madžarskem pa je celo legalizirana (Cukut Krilić in Zafošnik, 2020). Po drugi strani so NVO paralizirane zaradi samih omejitev gibanja med epidemijo kot tudi zaradi omejitve dostopa do begunskih centrov, pomoč ljudem na poteh pa je v nekaterih državah kriminalizirana ali vsaj stigmatizirana (Cukut Krilić in Zafošnik, 2020; Cukut Krilić, 2020a). Neodvisno spremljanje dogajanja je oteženo, saj novinarjem in aktivistom pogosto ni dovoljen vstop v centre ali pa jih morajo spremljati varnostniki ali predstavniki IOM (Cukut Krilić, 2020a). Kot poudarja prostovoljec iz NVO No Name Kitchen 
(v Cukut Krilić, 2020a), ki skuša beguncem v Srbiji in Bosni in Hercegovini zagotavljati hrano, druge potrebščine ter zatočišče na poti, so te osebe v času covida-19 še bolj izolirane, še manj vidne in posledično pozabljene od politikov in medijev. Brez podpore pa niso ostali le ljudje na balkanski poti. Na grških otokih je po besedah medicinske delavke iz NVO In-Sight (v Perner, 2020), ki je delovala v centru na otoku Hios, velika težava pomanjkanje osebja, morebitni prostovoljci pa v situaciji izolacije ne morejo priti na najbolj pomoči potrebne lokacije na terenu.

Drugi ključni problem na nivoju javnih politik je dostop do azila. Protimigrantski diskurz je bil $\mathrm{v}$ javnosti in $\mathrm{v}$ vladnih politikah večine držav na balkanski poti pogost že pred izbruhom virusa, $\mathrm{z}$ razglasitvijo izrednih razmer so se te prakse še izdatno okrepile. V Srbiji, denimo, z razglasitvijo izrednega stanja ni bilo več mogoče začeti azilnega postopka in/ali regularizirati bivanja, na ulicah, mejah in okoli begunskih centrov pa je bila vojska (Cukut Krilić, 2020a). Večkrat navajan primer dobre prakse portugalske vlade, ki je v času zdravstvene krize odredila, da so migranti pri dostopu do storitev socialnega in zdravstvenega varstva izenačeni z državljani, je model, ki omogoča, da ranljive skupine ne izpadejo iz sistema, predvsem da imajo dostop do javnega zdravstva. Slednje pa je ključni element boja proti pandemiji (Cukut Krilić, 2020a).

Ključni globalni akterji, zlasti UNHCR in IOM, tudi v sodelovanju z WHO, so se na zdravstveno krizo odzvali dokaj ažurno in v skladu z deklariranimi politikami skrbi, ki naj ne bi pozabile na nikogar (Vovk in Andlovic, 2020). Poudarek je na univerzalnem dostopu do zdravstvenih storitev, ki zajemajo preventivo, testiranje in zdravljenje beguncev, pri čemer je pomembno dejstvo, da so tri četrtine beguncev in migrantov po svetu ostale na območjih, kjer so zdravstveni sistemi že tako preobremenjeni in se posledično ne zmorejo uspešno soočiti s krizo (ibid.). Globalni akterji na področju podpore migrantom pa so v pandemiji imeli omejen domet, saj je bil navkljub poudarjanju zdravstvene preventive $\mathrm{v}$ begunskih namestitvah, skrbi za begunske otroke ipd. njihov mandat delovanja omejen že prostorsko, z njihovo prisotnostjo oziroma neprisotnostjo. Na izoliranih področjih, denimo na grških otokih, ki so pribežališče številnim beguncem, pa tudi na drugih globalnih žariščih, se jasno kaže, da je zdravstvena kriza tudi kriza mobilnosti, ki prinaša spremenjene vzorce preseljevanja, letalskih povezav, odnosov do tujcev ter režimov upravljanja meja in migracij (Vovk in Andlovic, 2020).

\section{Begunec kot kužni drugi}

Nadalje naju je zanimalo, kako se obstoječa sekuritizacija migracij navezuje in povezuje s sekuritizacijo zdravja, ki jo praviloma izvajajo nacionalne države, pri tem pa igra pomembno vlogo zgodovinsko trdno zasidrana 
ločnica do tujca kot morebitnega prinašalca bolezni. Tezo, da je begunec pogosto identificiran kot tisti, ki ogroža javno zdravje domače skupnosti, v naši raziskavi zelo jasno pokaže primer v turističnem kraju v Grčiji, ko je po novici o večjem številu okuženih nenadoma morala $v$ karanteno celotna lokalna skupnost, politika pa je v begunski center napotila večje število zdravstvenih delavcev. Izkazalo se je, da je panika pred okužbo z virusom covid-19 v lokalni skupnosti povezana s prostitucijo domačinov, ki so uporabljali spolne usluge begunk v lokalnem centru (Lihtenvalner, 2020).

Tovrstna homogenizacija skupnosti nasproti mladim ženskam, begunkam, je jasno pokazala meje zamišljene skupnosti, a tudi presečišča neenakosti glede na spol in raso, ki sta poleg družbenega razreda pomembna dejavnika družbenih razmejitev. Lokalna epidemija ksenofobije in rasizma se je zlila s seksizmom in za nastalo situacijo okrivila prebivalke begunskega centra - jim pripisala vlogo kužnega drugega; pri tem pa so izdatno pomagali številni mediji, ki so krivdo za razširitev okužb pavšalno pripisali migrantkam. Solidarnost do mladih žensk in kritiko moških iz lokalne skupnosti pa so izražali zgolj glasovi feminističnih skupin in redkih politikov (Lihtenvalner, 2020). Poudariti je treba razliko v skrbi za javno zdravje v tem primeru, ko je šlo za množična testiranja begunk in prisotnost zdravstvenih 80 delavcev, in vseh drugih primerih, ko je za nekaj sto tisoč beguncev v Grčiji (predvsem na otokih Lezbos, Hios in Samos) skrb za njihovo javno zdravje popolnoma marginalizirana družbena tema.

Podobni situaciji smo priča v Italiji, zlasti ob njeni severni meji s Slovenijo, kjer oblasti predvsem "negujejo retoriko varovanja meje pred begunci (Lešnik, 2020). Kaj se dogaja v množičnih zaprtih begunskih centrih v Italiji in vzdolž celotne balkanske migracijske poti, pa je $\mathrm{v}$ času pandemije virusa covid-19 prej nejasno kot jasno. Četudi je Italija v globalnem oziru veljala za eno največjih žarišč novega korona virusa, pa ta zaznamovanost očitno ne spreminja dosedanjih politik do migrantov (ibid.). Nadalje, v Sloveniji je bilo le vprašanje časa, kdaj bo v retoriki vladajoče stranke prišlo do prekrivanja vprašanj javnega zdravja zaradi virusa covid-19 ter kontinuirane politike zavračanja beguncev. Pričakovano se je zgodilo hitro. Kot pokaže Vezjak (2020), gre za od t.i. begunske krize leta 2015 trajajoč proces psihopolitike zastraševanja pred begunci, pri čemer ima v tej propagandi osrednje mesto reprezentacija begunca kot kužnega. Če je kdo kužen, pravzaprav to mora biti begunec, v kontekstu covida-19 pa se je politični kužnosti pridružila »otipljiva«, biološka in zdravstvena kužnost (Vezjak, 2020), s čimer se dodatno legitimizira mitologija o beguncih kot prenašalcih bolezni, tistih torej, ki imajo tifus, garje, zdaj pa prenašajo covid-19. A ne gre le za ideologijo ali politično propagando določene politične struje, imun poenostavljenim sklepanjem ni ostal niti resen politični tisk. Osrednji dnevnik na primer objavi naslov »Ali migranti povečujejo tveganja za prenos virusa«, s čimer s 
tezo o kužnosti neposredno podpira namero vlade po krepitvi vloge vojske na meji (Vezjak, 2020), medtem ko so provladni mediji tezo o beguncih kot prenašalcih virusa ves čas zdravstvene krize odkrito zagovarjali.

A kužni drugi so v času epidemije covida-19 lahko postali številni posamezniki in posameznice, ki niso ustrezali prevladujočemu modelu bivanja in družbeno pričakovanim ravnanjem, tudi npr. brezdomci širom evropskih mest, delavci, ki so se vračali z gradbišč in s kmetijskih delovišč severne Italije proti Romuniji in Bolgariji, delavci iz Srbije, ki so ostali ujeti na poti in so pred ambasado v Ljubljani zahtevali, da jih matična država sprejme itd. (Zavratnik, 2020a; 2020b). Globalna pandemija covida-19 je begunce in migrante postavila v dodatno ranljiv položaj, ker so bile prekinjene običajne poti in je zastoj mobilnosti še povečal negotovost glede nadaljevanja le-teh. A se je pokazala tudi zanimiva - $\mathrm{v}$ resnici pa že dalj časa prisotna - ambivalentnost v odnosu do mobilnosti migrantov: nekateri so bili prisiljeni ostati (npr. begunci v centrih), medtem ko drugi, v tem času zelo iskani sezonski delavci iz vzhodne Evrope in Balkana, niso mogli priti (Cukut Krilić, 2020c; Zavratnik in Perner, 2020). Jasno je, da so migranti in migrantke kot delavci izjemno pomembni za delovanje sodobnih družb. To dejstvo ni nič novega, a bi pandemija in spremljajoča družbena kriza morali biti priložnost za resen premislek o (pre)vrednotenju dela, vključno z delom migrantov in migrantk (Cukut Krilić, 2020c; Zavratnik 2020b).

\section{Novi rasizmi in nove izključenosti}

V tretjem sklopu raziskave naju je zanimalo, kako je pandemija covida-19 posegla $\mathrm{v}$ obstoječe neenakosti in obenem producirala nova razlikovanja $\mathrm{v}$ polju rasizma in nacionalizma. $Z$ novimi rasizmi $\mathrm{v}$ tem kontekstu mislimo na vznik in utrjevanje tistih novih rasizmov in izključevanj, ki koreninijo $\mathrm{v}$ pandemiji in v njenih nosilcih kužnih drugih, pri čemer slednje ne pomeni, da so zato npr. črnska telesa migrantov kaj manj podvržena že obstoječim rasizmom. Na mestu je vprašanje, kako se bodo nova izključevanja ohranila v družbenem kolektivnem spominu onkraj globalne zdravstvene krize. In nadalje, ali se bodo posledično spremenile interakcije med ljudmi, se bomo denimo za vsak primer izogibali vseh Azijcev, ker ne prepoznamo zanesljivo Kitajcev, ali pa se bodo rasizmi okrepili kar do vseh prebivalcev Daljnega vzhoda (Vovk et al., 2020)? Ali pa se bo morda razvila nova oblika paranoidnega rasizma, ko se bomo, v strahu pred virusom covid-19, distancirali vsi od vseh? Bomo priča novi praksi, ki rasistično obravnava tiste, za katere se je doslej zdelo, da ne morejo biti njegovi naslovniki, npr. Italijani? Zdi se, da se neke vrste »rasistični obrat" pravzaprav že dogaja. Ne le da je "sumljivi drugi« Italijan v evropskem prostoru, je tudi Afričan na Kitajskem (Vovk et al., 2020). 
Analiza Martine Bofulin (2020) kaže, da je biti Kitajec v času virusa covid19 večdimenzionalna in kompleksna realnost, pri čemer je zelo pomembno analizirati mobilnost kitajskih državljanov v mednarodnem prostoru, a tudi gibanje povratnikov, torej tistih, ki se iz tujine vračajo v domače skupnosti. Izključevanja namreč gredo v vse smeri; prav tako kot Kitajci v tujini jih doživljajo povratniki s strani svojih sodržavljanov, enako pa velja tudi znotraj diaspor. O podobnih praksah izključevanja poročajo tudi raziskovalci v Indiji, ko gre za vračanje delavcev migrantov v domače kraje, kjer so jih pogosto pričakale grožnje, ustrahovanje in sporne prakse (npr. škropljenje z insekticidi, belilom ipd.), s katerimi naj bi domače prebivalstvo zaščitili pred virusom (Cukut Krilić, 2020b), preden so sploh lahko vstopili na domače območje. Poročajo tudi o fizičnih napadih na migrante, saj naj bi bili ti kontaminirani z virusom od zunaj (ibid.).

Pri obravnavi rasizma ni toliko ključno, kdo je nov ali star naslovnik oziroma koga na individualni ravni prepoznamo kot (nov) objekt rasistične zaznave. Gre predvsem za sistemsko raven, v tem primeru predvsem za zasidranost rasizma v zdravstvenih praksah, pri čemer se rasistični učinki kažejo v slabši zdravstveni oskrbi in dostopu do zdravstvenih storitev različnih družbenih manjšin. Podatki kažejo, da so prav te manjšine, ki v naj82 večji meri izkušajo institucionalni rasizem, v večji meri žrtve novega korona virusa, kar je povezano z njihovim slabšim socialnim in ekonomskim položajem, revščino delavskega razreda in dostopom do institucij javnega zdravstva (Ploštajner, 2020). Zato je treba odločno zavreči mit o tem, da smo v pandemiji covida-19 vsi v istem čolnu. Nasprotno, pandemija je družbene neenakosti potencirala in hkrati še bolj očitno razgalila kopičenje neenakosti skozi presečišča družbenega razreda, rase ali etničnosti in dostopa do zdravstvenega sistema. Razredna delitev je tako rekoč vpisana v človeška telesa in se odraža v krajši življenjski dobi in slabšem zdravstvenem stanju revnejših, revni in manj zdravi pa so bolj podvrženi zapletom pri okužbi z virusom covid-19. Kot ugotavlja Ploštajner (2020), podatki iz ZDA potrjujejo, da se razredna in rasna razmerja močno prekrivajo. Podobno ugotavljajo tudi raziskovalci iz Indije, ki uvodoma v zborniku Meje epidemije (v Cukut Krilić, 2020c) poudarijo, da epidemija, ukrepi za nadzorovanje širjenja virusa in geopolitika še nikoli niso bili tako zelo povezani, hkrati pa je pandemija razkrila desetletja slabih politik na področju zdravstva (ibid.).

\section{Sklep}

V članku analizirava odnos med pandemijo virusa covid-19, migracijami in izključenostjo iz varnega prostora bivanja. Izhajava iz predpostavke, da so meje pandemije postale tudi meje mobilnosti oziroma da je s korona krizo sedentarnost postala nov imperativ globalne mobilnosti. Do nedavnega 
nepredstavljiv zastoj mobilnosti, ki se je zgodil na globalni ravni, je skozi geslo \#ostanidoma kot temeljnim odzivom na obvladovanje pandemije prinesel zaprtje v meje nacionalnih držav ali še manjših enot (regij, okrajev, občin, sosesk, ponekod celo ulic ali bivanjskih objektov), pri čemer je prišlo do povsem novega tipa družbenega dogovora o režimu mobilnosti.

V besedilu se ukvarjava $\mathrm{z}$ ožjim vidikom restrukturirane mobilnosti, to je $\mathrm{z}$ mednarodnimi migracijami in begunskimi potmi $\mathrm{v}$ času, ko so meje postale neprehodne za vse, ne le za begunce, hkrati pa se vprašanju prehajanja meja pridruži še strašljiva dvojica kužnega drugega. V analizi naju zanimajo tri vprašanja $\mathrm{v}$ odnosu med pandemijo in (mednarodnimi) migracijami: 1. odzivi javnih politik na spremenjene režime prehajanja nacionalnih meja, 2. nocija begunca kot kužnega drugega (tj. potencialnega prenašalca virusa) ter 3. novi rasizmi in izključevanja, ki jih poraja pandemija. Skozi to prizmo zagovarjava tezo, da imperativ \#ostanidoma kot ključni pristop delovanja protikoronskih politik $v$ veliki meri spregleda oziroma ne poskrbi za ranljive družbene skupine in številne posameznike na družbenem robu; slednje velja tudi za migrante in begunce, kar pokaževa predvsem na primeru ljudi na tako imenovani balkanski poti.

Analiza odzivov javnih politik na pandemijo covid-19 je pokazala, da se je negotov položaj beguncev in migrantov še povečal, ker so bile prekinjene običajne prostorske poti in je zastoj mobilnosti še povečeval negotovosti nadaljevanja poti ali morebitne odreditve karantene. Običajnim tveganjem na poteh (npr. nedokumentirano prehajanje meja, izpostavljenost fizičnemu ali psihičnemu nasilju, rasistične obravnave ipd.) se je pridružilo še povečano zdravstveno tveganje, saj je bil tudi dostop do zdravstvenih storitev omejen ali povsem onemogočen. Nadalje se je pokazalo, da je bil ljudem na poti $\mathrm{v}$ veliki meri omejen dostop do azilnega postopka ter da niso imeli celovitih informacij o pandemiji in o svojih pravicah $v$ tem kontekstu. Redke države, vzorčni primer je Portugalska, so podelile pravice do zdravstvene in socialne oskrbe vsem migrantom in migrantkam na njihovih ozemljih, ne glede na klasificiranje različnih politično zamišljenih kategorij migrantov, kar je nedvomno zmanjšalo njihovo ranljivost.

Naslednja analizirana relacija se nanaša na meje, ki so v kontekstu pandemije postale neprehodne za vse, ne le za ljudi na poti. Slednji, migranti in begunci, so postali del zaznamovanega telesa kužnega drugega. Retorike nacionalističnih politik v globalnem oziru in "vaške straže« na lokalnih nivojih so jih jasno opredelile kot tveganje javnemu zdravju. Pri tovrstni prezrtosti določenih družbenih skupin in njihovi stigmatizaciji so se kot pomembna pokazala presečišča družbenega razreda, rase in etničnosti in dostopa do sistema javnega zdravstva. Migranti so se torej znašli v situaciji dvojne izključitve: pogosto niso vključeni v ukrepe/mehanizme zagotavljanja varne izolacije v primeru okuženosti, hkrati pa so percipirani kot del telesa kužnega 
drugega in kot taki seveda niso dobrodošli. Dvojna izključenost migrantov $\mathrm{v}$ primerjavi z domačim prebivalstvom še dodatno potencira njihov ranljiv položaj in povečuje tveganja.

Tretje raziskovalno vprašanje zadeva nove rasizme in izključevanja, ki jih je pandemija še zaostrila, saj so tarča novih diskriminacij postale tudi skupine prebivalstva oziroma poklicne skupine (npr. zdravstveni delavci), ki so bile prepoznane kot nosilci virusa covid-19. Med pandemijo so podobne oblike diskriminacije in kriminalizacije kot migranti izkusile tudi druge skupine državljanov, na primer tisti, ki so bili solidarni z begunci, ali tisti, ki so bili po videzu (na primer barvi kože) percipirani kot nosilci virusa, kar je povečevalo ranljivosti različnih skupin prebivalstva, tudi državljanov.

Spomniti velja, da je Bridget Anderson (2019) že pred pandemijo pisala o nujnosti »migrantizacije« državljana, kar nam pomaga uvideti povezave in podobnosti med formalnimi izključevanji nedržavljanov in pogostimi oblikami neformalnih izključevanj državljanov. Če so omejitve gibanja postale nova normalnost za (skorajda) vse, saj je regularnih poti za mobilnost še manj kot pred pandemijo (Yayboke, 2020) - kako torej misliti položaj ljudi na poti, ki jim »režimi mobilnosti« (Glick Schiller in Salazar, 2013) postavljajo nove in nove ovire za gibanje in jasno začrtujejo meje med privilegirano

84 in stigmatizirano (ne)mobilnostjo (ibid.)? Spregled ranljivih skupin - tako v pandemiji kot onkraj oziroma pred njo - pa vedno jasno kaže širšo tendenco: torej, da če so, kot pravi Bridget Anderson (2019), določene rešitve slabe za migrante, je zelo verjetno tudi, da so slabe za državljane.

\section{LITERATURA}

Anderson, Bridget (2019): New directions in migration studies: towards methodological de-nationalism. Comparative Migration Studies 7 (36). Dostopno prek

https://comparativemigrationstudies.springeropen.com/articles/10.1186/s40878019-0140-8\#citeas (16. 6. 2020).

Bofulin, Martina in Romana Bešter (2010): Enako zdravstvo za vse? Imigranti v slovenskem zdravstvenem sistemu. V: Mojca Medvešek in Romana Bešter (ur.), Državljani tretjih držav ali tretjerazredni državljani?: integracija državljanov tretjih držav v Sloveniji, 270-311. Ljubljana: Inštitut za narodnostna vprašanja.

Bofulin, Martina (2020): Kitajski migranti in covid-19 - mobilnost in izključevanje med pandemijo. Dve domovini/Two Homelands 52: 95-111.

Dingwall, Robert, Lily M. Hoffman in Karen Staniland (2013): Introduction: Why a Sociology of Pandemics? Sociology of Health and Illness 35 (2): 167-173.

Glick Schiller, Nina in Noel B. Salazar (2013): Regimes of mobility across the global. Journal of Ethnic and Migration Studies 39 (2): 183-200.

Greenaway, Christina in Brian D. Gushulak (2017): Pandemics, migration and global health security. V: Philippe Bourbeau (ur.), Handbook on Migration and Security, 316-336. Cheltenham: Edward Elgar Publishing. 
Guadagno, Lorenzo (2020): Migrants and the COVID-19 epidemic: an initial analysis. IOM. Dostopno prek https://publications.iom.int/system/files/pdf/mrs-60. pdf (18. 6. 2020).

Lipovec Čebron, Uršula (2010): The construction of a health uninsurant: People without medical citizenship as seen by some Slovene health workers. Studia Ethnologica Croatica 22: 187-212.

McDonnell, Emily (2020): Will COVID-19 finally force us to reconsider the Global (Im)mobility regime. Dostopno prek https://rli.blogs.sas.ac.uk/2020/04/16/ will-Covid-19-finally-force-us-to-reconsider-the-global-immobility-regime/ (19. 6. 2020).

Molnar, Petra (2020): Technology, migration and illness in the times of COVID-19. Dostopno prek https://edri.org/technology-migration-and-illness-in-the-timesof-Covid-19/ (19. 6. 2020).

Pertek, Sandra, Jenny Phillimore in Pip McKnight (2020): Forced migration, SGBV and COVID-19 Understanding the impact of COVID-19 on forced migrant survivors of SGBV, Refugee Women Connect, University of Birmingham, Institute for Research into Superdiversity. Dostopno prek https:/www.birmingham.ac.uk/ Documents/college-social-sciences/social-policy/iris/2020/sgbv-Covid-19.pdf (18. 6. 2020).

Scott, Penelope, Dennis Odukoya in Hella von Unger (2014): The Classification of "Migrants« as a Discursive Practice in Public Health. A Sociology of Knowledge Approach. Discussion Paper. Wissenscaftszentrum Berlin für Sozialforschung. Dostopno prek https://bibliothek.wzb.eu/pdf/2014/iii14-601.pdf (10. 6. 2020).

Vignier, Nicolas in Olivier Bouchaud (2018): Travel, migration and emerging infectious diseases. The Journal of the International Federation of Clinical Chemistry and Laboratory Medicine 29 (3): 175-179.

Yayboke, Erol (2020): Five Ways COVID-19 Is Changing Global Migration. Dostopno prek https://www.csis.org/analysis/five-ways-Covid-19-changingglobal-migration (17. 6. 2020).

Zavratnik, Simona, Rebeka Falle Zorman, Živa Broder (2017): Javno mnenje in migracije: mehanizmi klasifikacij in »begunska kriza«. Teorija in praksa 54 (5): 857-884.

Zavratnik, Simona in Sanja Cukut Krilić (2018): Addressing Intersectional Vulnerabilities in Contemporary Refugee Movements in Europe. Družboslovne razprave 87: 85-106.

Zavratnik, Simona in Sanja Cukut Krilić (2020): Digitalni begunci. Transformacije migracijskih poti ali ko pametni telefon nadomesti kovček. Ljubljana: Založba FDV in Založba ZRC.

\section{VIRI}

Cukut Krilić, Sanja (2020a): Webinar: VPLIV COVID-19 NA BALKANSKI POTI. Dostopno prek https://virusnimameja.com/2020/05/12/webinar-vpliv-Covid19-na-balkanski-poti/ (20. 6. 2020). 
Cukut Krilić, Sanja (2020b): Recenzija zbornika: Meje epidemije: Covid-19 in migrantski delavci in delavke. Dostopno prek: https:/virusnimameja.com/ 2020/05/21/recenzija-zbornika-meje-epidemije-Covid-19-in-migrantski-delavciin-delavke/ (20. 6. 2020).

Cukut Krilić, Sanja (2020c): Trije D-ji oskrbe s hrano. Dostopno prek https://virusnimameja.com/2020/04/19/trije-d-ji-oskrbe-s-hrano/ (24. 6. 2020).

Cukut Krilić, Sanja in Anja Zafošnik (2020): Webinar o beguncih na balkanski poti v času COVID-19. Dostopno prek https://virusnimameja.com/2020/04/25/webinar-o-beguncih-na-balkanski-poti-v-casu-Covid-19/ (21. 6. 2020).

Lešnik, Pia (2020): Italija in begunci: v mesta ali v begunska taborišča?. Dostopno prek https:/virusnimameja.com/2020/06/04/italija-in-begunci-v-mesta-ali-vbegunska-taborisca/ (20. 6. 2020).

Lihtenvalner, Katja (2020): Grška epidemija ksenofobije in rasizma. Dostopno prek https:/virusnimameja.com/2020/05/23/grska-epidemija-ksenofobije-inrasizma/ (20. 6. 2020).

Perner, Špela (2020): S terena: Pogovor s prostovoljko v grških begunskih centrih. Dostopno prek https://virusnimameja.com/2020/04/07/iz-terena-pogovor-sprostovoljko-v-grskih-begunskih-centrih/ (23. 6. 2020).

Perner, Špela in Anja Zafošnik (2020): Webinar: Kaj pandemija COVID-19 pomeni za begunce po svetu. Dostopno prek https://virusnimameja.com/2020/04/07/ webinar-kaj-pandemija-Covid-19-pomeni-za-begunce-po-svetu/ (22. 6. 2020).

86 Ploštajner, Klemen (2020): \#Ostanidoma: ali mit o istem čolnu. Dostopno prek https://virusnimameja.com/2020/04/15/ostanidoma-ali-mit-o-istem-colnu/ (25. 6. 2020).

UNHCR (The UN Refugee Agency) (2020): Live blog: Refugees in the Covid-19 crisis. Dostopno prek https://www.unhcr.org/news/stories/2020/4/5e79e2410/ live-blog-refugees-Covid-19-crisis.html (22. 6. 2020).

Vezjak, Boris (2020): Begunci, koronavirus in propaganda. Dostopno prek https:// virusnimameja.com/2020/05/28/begunci-koronavirus-in-propaganda/ (20. 6. 2020).

Vovk, Špela in Klara Andlovic (2020): Begunci v COVID-19 krizi: odziv globalnih akterjev. Dostopno prek https://virusnimameja.com/2020/04/07/begunci-vCovid-19-krizi-odziv-globalnih-akterjev/ (21. 6. 2020).

Vovk, Špela, Klara Andlovic in Simona Zavratnik (2020): COVID-19 sovraštvo: kaj pa vprašanje rasizma v zdravstvu?. Dostopno prek https://virusnimameja. com/2020/05/14/Covid-19-sovrastvo-kaj-pa-vprasanje-rasizma-v-zdravstvu/ (24. 6. 2020).

Zafošnik, Anja (2020a): S terena: delo z begunci na Balkanu v času razmaha Covid19. Dostopno prek https://virusnimameja.com/2020/05/10/s-terena-delo-zbegunci-na-balkanu-v-casu-razmaha-Covid-19/ (23. 6. 2020).

Zafošnik, Anja (2020b): Nevladne organizacije in COVID-19. Zakaj so (lahko) pomembne za migrante, begunce, nas?. Dostopno prek https://virusnimameja. com/2020/04/08/nevladne-organizacije-in-Covid-19-zakaj-so-lahko-pomembneza-migrante-begunce-nas/ (20. 6. 2020). 
Zavratnik, Simona (2020a): \#StayHome. A privilege not afforded to refugees and migrants on the routes. Dostopno prek https://virusnimameja.com/2020/04/07/ stayhome-a-privilege-not-afforded-to-refugees-and-migrants-on-the-routes/ (23. 6. 2020).

Zavratnik, Simona (2020b): Drugi, kužni: ljudje z družbenega obrobja v času Covid19. Dostopno prek https://virusnimameja.com/2020/04/08/drugi-kuzni-ljudjez-druzbenega-obrobja-v-casu-Covid-19/ (23. 6. 2020).

Zavratnik, Simona in Špela Perner (2020): Sezonsko delo: Pivo, solata in natakar, ki ju prinese na mizo. Dostopno prek https:/virusnimameja.com/2020/04/26/ sezonsko-delo-pivo-solata-in-natakar-ki-ju-prinese-na-mizo/ (23. 6. 2020). 